\title{
UCL Holding ISBN 9788366675599
}

\author{
UCL Library
}

Aug 31, 2021

https://ucl-new-primo.hosted.exlibrisgroup.com/permalink/f/5qfvbu/UCL LMS DS51350493170004761

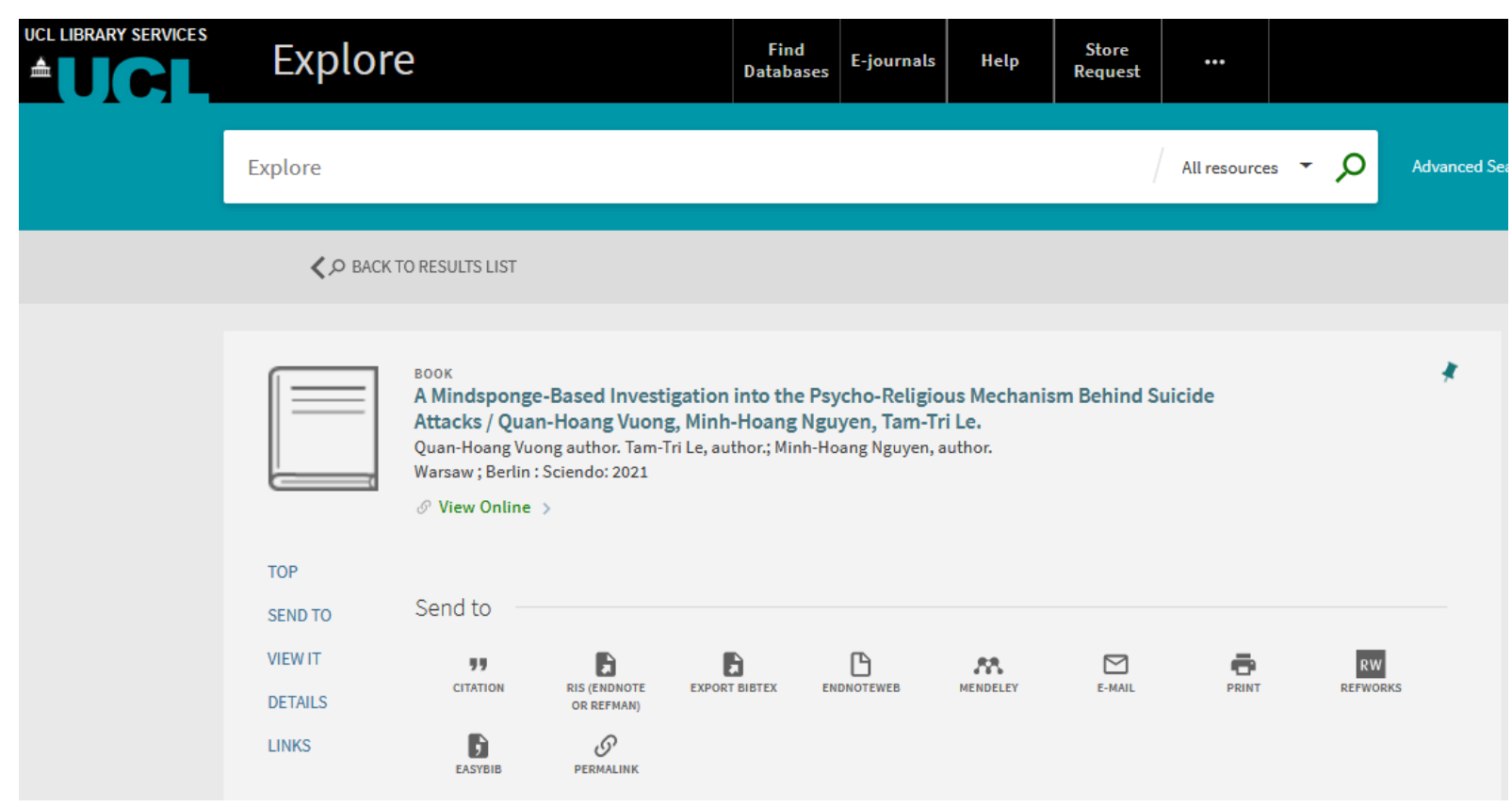


A Mindsponge-Based Investigation into the Psycho-Religious Mechanism Behind Suicide Attacks / Quan-Hoang Vuong, Minh-Hoang Nguyen, Tam-Tri Le.

- Author: Quan-Hoang Vuong author.

- Contributor: Tam-Tri Le, author.; Minh-Hoang Nguyen, author.

- Publisher: Warsaw; Berlin : Sciendo

- Creation Date: 2021

- Identifier: ISBN: \$\$V9788366675599; ISBN: \$ \$V9788366675582

- Format: 1 online resource (127 p.).

- Language: English

- Notes: - Electronic reproduction. Berlin : Walter de Gruyter GmbH, C2021. Available in PDF and EPUB formats. Description based on contents viewed 9 August 2021.; In English.

- UCL local notes: uclebkebadegruyter201803 mrcebadegruyter20210809; UCL username and password required for access.

- (UCL internal use only): 9931183884404761 